\title{
Responses of farmed silver foxes (Vulpes vulpes) to excessive food availability: Implications for using food as a yardstick resource in motivation tests
}

\author{
Anne Lene Hovland ${ }^{\mathrm{a}, *}$, Georgia Mason $^{\mathrm{b}}, \emptyset_{\text {ystein Ahlstrøm }}^{\mathrm{a}}$, \\ Morten Bakken ${ }^{a}$

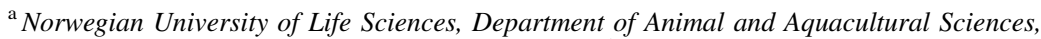 \\ P.O. Box 5003, N-1432 As, Norway \\ ${ }^{\mathrm{b}}$ Department of Animal \& Poultry Science, University of Guelph, Ontario, Canada N1G 2W1
}

Accepted 29 October 2006

Available online 28 November 2006

\begin{abstract}
Food is frequently used as a 'yardstick' in operant experiments. However, previous work on silver foxes had suggested that how food is presented can affect how they respond to it, with excess food leading to variable consumption rates, and cages containing food being avoided over control cages except while eating. Our first experiment therefore examined foxes' consumption of excess food in more detail by comparing their daily intakes with foxes fed a control diet for 4 weeks. Eighteen silver fox vixens were assigned to one of two groups in which the experimental group $(N=9)$ was feed 2.5 times that of control $(N=9)$. Although appetite, measured as the amount of food consumed, tended to fluctuate none of the overly fed foxes stopped eating during the experimental period. On average, the excessive fed group consumed more food $(317 \pm 18 \mathrm{~g} /$ day $)$ compared to the controls $(273 \pm 12 \mathrm{~g} /$ day $)$.

In Experiment 2 we aimed to test whether the presence of excess food affected the foxes' use of the cage. Five silver fox males were housed in separate multi-compartment apparatuses and the position of a food bowl was randomly switched between two cages for 18 days. The subjects had to perform one operant response to enter each cage and time inside the compartments was calculated. The foxes spent significantly less time in the food compartment ( $4 \mathrm{~h} 13 \mathrm{~min}$ ), compared to the empty cage ( $12 \mathrm{~h} 12 \mathrm{~min}$ ) and as expected by random $(8 \mathrm{~h})(P<0.05)$. These results confirm that ad libitum fed silver foxes have a more fluctuating intake rate than animals fed just below maintenance, and that placing food in a cage reduces the time spent there. The day-to-day use of food, and perhaps even its value, can therefore be shaped by how it is presented. Implications for using food as a yardstick resource for silver foxes is that the ration should be held at
\end{abstract}

\footnotetext{
* Corresponding author. Tel.: +1 47649651 68; fax: +1 4764965101.

E-mail address: anne.hovland@umb.no (A.L. Hovland).
} 
maintenance. Also, to control for a motivation to leave food positioned in the operant test cage a free control cage distant from food could be provided.

(C) 2006 Elsevier B.V. All rights reserved.

Keywords: Operant methods; Food; Yardstick; Motivation; Appetite; Silver fox

\section{Introduction}

Using operant methods for measuring motivational strength is a common procedure for investigating animals' preferences for various types of resources (e.g. Dawkins, 1983; Matthews and Ladewig, 1994; Mason et al., 2001), with food often being used as a high-value reference or 'yardstick' resource (e.g. Pedersen et al., 2002; Warburton and Mason, 2003). To examine farmed foxes motivational strength our research group developed an operant apparatus where foxes could work (by pulling a loop) for access to various resources (Hovland, 2005). Our main measure of motivation was the maximum price paid, which was the highest number of pulls foxes were willing to pay before giving up access for $24 \mathrm{~h}$. Although this apparatus ultimately worked well (Hovland et al., 2006), much pilot work was needed to refine the methodology. Our refinement and validation of the apparatus is described elsewhere (Hovland, 2005; Hovland et al., 2006), but here we examine how the presentation of the useful yardstick 'food' could affect how it is used by foxes and perhaps even valued.

During the initial operant experiment that aimed to evaluate the maximum price paid as a measure of foxes' motivation our concerns were raised by two observations: The first was that when ad libitum food was used as a 'yardstick' resource the foxes' daily food intake decreased with succeeding time, possibly affecting the subjects' feeding motivation. Moreover, the results showed that some of the foxes ranked food the least important resource (Hovland, 2005). This suggested that if food is offered ad libitum, foxes might have periods of gorging and of relative fast, a factor potentially adding great day-to-day variability to measures of motivation. In contrast, when we offered food in more limited quantities, the foxes' value of food was closer to our predictions and day-to-day food-use was also more consistent (Hovland et al., 2006). If silver foxes are sensitive to the amount of food provided and this leads to periods where subjects stop eating for more than the 'cut off' period (e.g. $24 \mathrm{~h}$ ) used to determine their maximum price, this may generate artefactually low measures of feeding motivation, rendering food less useful as a 'yardstick' in our operant set-up. For example, the blue or arctic fox (Alopex lagopus) can fast for up to 3 weeks (Nieminen et al., 2001), although this kind of functional adaptation may be less evident in the red fox, with its different foraging niche and typical habitat. Yet, since several factors suggested that amount of food offered could affect the subjects' appetite, more information was needed on how silver foxes really do respond to excess food. Thus, our first aim was to test whether access to excessive amounts of food during an extended period of time affected the appetite of farmed silver foxes because of its implications for using food motivation as a yardstick in our operant apparatus for foxes.

The second observation to attract our notice was that the foxes spent significantly less total time inside the resource cage when food was present compared to when the resource cage was empty (Hovland, 2005; Hovland et al., 2006). This was unexpected because it was not likely that the presence of a food tray, occupying roughly $3 \%$ of the total floor area, should negatively affect the subjects' opportunity to use the cage floor for resting or active behaviours. Apparently, food shaped how the cage was used, and surprisingly, it seemed as though the food was avoided 
except when it was being eaten. Consequently, our second aim was therefore to replicate this in a more controlled experiment to test if foxes actively avoided the food cage. If confirmed, this finding could affect silver foxes operant motivation to work for access to other resources (e.g. a social companion) when food is present ad libitum in the operant cage, due to an elevated motivation to leave the cage containing food. Also, the study could more generally reflect the feeding patterns of an animal that is naturalistically opportunistic (e.g. Kauhala et al., 1998), which competes over food and frequently will cache surplus food (e.g. Macdonald, 1976).

\section{Experiment 1: does the presence of excessive food affect appetite in silver foxes?}

\subsection{Materials and methods}

\subsubsection{Animals and housing}

Eighteen barren 2-year-old silver fox vixens (female fox) from a commercial Norwegian line participated in the study. The vixens were randomly assigned to one of two groups, nine vixens in the experimental group and nine vixens that acted as controls. The average body weight of the two groups did not differ at the start of the experiment and ranged from 7.3 to $5.6 \mathrm{~kg}$, with a mean of $6.47 \pm$ S.E. 0.11 . All vixens were singly housed in a standard wire mesh cage measuring $0.8 \mathrm{~m} \times 1.1 \mathrm{~m} \times 1.2 \mathrm{~m}$ in an uninsulated shed for farm foxes. Each vixen had access to a mesh resting shelf and continuous access to drinking water during the study.

\subsubsection{Experimental procedure}

A standard food paste for fur animals (Pelsdyrfôr Hamar AB) was used for the study. The average metabolizable energy content was $108 \pm$ S.E. $1.92 \mathrm{kcal} / 100 \mathrm{~g}$ (www.norpels.no/viewdoc.asp?doc). Prior to the start of the experiment the control group were fed $350 \mathrm{~g}$ food once a day for 8 days $(25 / 03-01 / 04)$ to establish the amount of food needed for maintenance. Concurrently, the experimental group was fed $1000 \mathrm{~g}$ for 8 days in order to establish the amount of food needed to ensure food leftovers. The mean consumption was $437 \pm$ S.E. $39 \mathrm{~g}$ in the excessive fed group and $327 \pm$ S.E. $8 \mathrm{~g}$ in the control group. During the experiment the controls were given $300 \mathrm{~g}$ of food once a day to avoid leftover food. For the experimental group $750 \mathrm{~g}$ food was provided once a day during the experiment. Leftover food was removed from the food tray in both groups prior to the provisioning of fresh food each day. The vixens were previously habituated to the presence of people by repeatedly hand feeding of titbits. The foxes were habituated to the feeding procedure for 8 days prior to the start of the experiment and they were fed to the same time each day and by persons familiar to them. The study was conducted at the University Fur Animal Research Farm (Centre for Farm Animal Research, SHF) from 02 April to 29 April 2004.

\subsubsection{Data collected}

Food leftovers were weighed each day and food consumption was calculated for each fox per day and group. The body weight of the vixens was recorded at the start and at the end of the experiment in order to test whether the feeding regimes affected weight gain. Metabolic body weight (body weight $\mathrm{kg}^{0.75}$ ) was calculated as average of initial and final body weight.

\subsubsection{Statistical analysis}

The effect of time on food consumption was analysed using the mixed model consumption $=$ treatment $_{1,2}+$ fox $_{1-18}+$ day $_{1-28}+$ body weight $_{\text {start }}+\left(\right.$ treatment $_{1,2} \times$ day $\left._{1-28}\right)$, defining fox as a random effect. A Satterthwait approximation was used for calculation of the denominator degrees of freedom (Littell et al., 1996). The average amount of food consumed per day during the entire period was calculated for each subject and was analysed with the model mean consumption $=$ treatment $_{1,2}+$ body weight $_{\text {start }}+$ (treatment $_{1,2} \times$ body weight $_{\text {start }}$ ). We tested whether the two feeding regimes affected body weight gain in the foxes by calculating the difference between the body weight at the start and the end of the experiment. 
This value (weight difference) was analysed with the model weight difference $=$ treatment $_{1,2}+$ body weight $_{\text {start }}+\left(\right.$ treatment $_{1,2} \times$ body weight $_{\text {start }}$ ). Standard $t$-tests were used to compare differences of means. All mean values are given with standard errors (S.E.). SAS ${ }^{\mathbb{R}}$ Enterprise GuideV2 was used for the statistical analyses.

\subsection{Results}

There was a significant effect of treatment $\left(F_{1,25.8}=10.08, P=0.004\right)$ and time $\times$ treatment $\left(F_{1,483}=7.73, P=0.006\right)$ on the food consumption, i.e. the amount of food consumed decreased with time in the excessive fed foxes, but not in the controls (Fig. 1). When excluding the nonsignificant interaction effect treatment $\times$ body weight $_{\text {start }}$ from the model there was a tendency towards a higher average level of food consumption in the excessive fed foxes $(317.5 \pm 18.5 \mathrm{~g} /$ day) compared to the controls $(273.5 \pm 11.9 \mathrm{~g} /$ day $)$ for the whole experimental period $\left(F_{1,15}=4.33, P=0.055\right)$. This food intake corresponds to $368.8 \pm 57.3 \mathrm{~kJ} / \mathrm{kg}^{0.75}$ day and $318.6 \pm 33.9 \mathrm{~kJ} / \mathrm{kg}^{0.75}$ day, respectively.

There was no significant difference in body weight between the groups at the end of the experiment ( $t$-test: $t_{16}=0.06, P=0.952$ ). In both groups the subjects had lost weight during the period, and there was no significant difference between the groups ( $t$-test: $t_{16}=0.33, P=0.743$ ). Thus, the average weight loss was $0.67 \pm 0.10 \mathrm{~kg}$ and the mean body weight at the end of the experiment was $5.81 \pm 0.09 \mathrm{~kg}$. The heavier subjects tended to loose more weight than the lighter ones $\left(F_{1,14}=9.75, P=0.008\right)$ which was most pronounced in the excessive fed subjects (experimental group: $F_{1,7}=9.63, P=0.017$, controls: $F_{1,7}=2.99, P=0.128$ ).

\subsection{Discussion, experiment 1}

The results showed that although on average the excessive fed subjects tended to consume more food compared to the controls, the amount consumed decreased with succeeding time. Furthermore, there was more day-to-day variation in appetite in the ad libitum fed foxes, although none of these subjects stopped consuming food during the experimental period. Overall, the feeding regime affected appetite on a daily basis but had reduced effects on the long-term motivation to feed. Interestingly, the data showed that all subjects lost weight during the experimental period, independent of the feeding regime. The energy maintenance level for silver foxes is not yet established, however, in dogs daily energy maintenance level is $523 \mathrm{~kJ} \mathrm{ME} / \mathrm{kg}^{0.75}$ (Burger, 1993). During the experimental period the control group and the experimental group

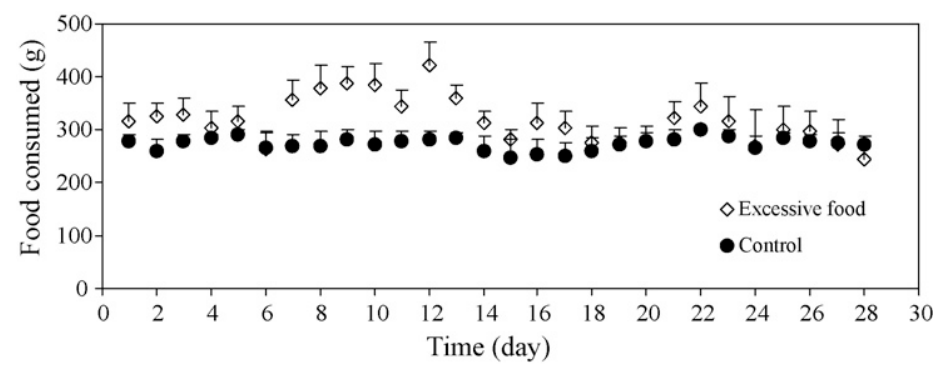

Fig. 1. The mean food consumption $( \pm$ S.E.) in the excessive feed subjects and the controls with succeeding time in Experiment 1 . The consumption rate of excessive fed foxes was more fluctuating (coefficient of variation $(\mathrm{CV})=35.3$ ) compared to the controls $(\mathrm{CV}=20.5)$. 
consumed ME 39\% and 30\% below this level, respectively, thus supporting the body weight reduction observed for all animals. Even though the experimental subjects tended to consume more food this did not increase their capacity to maintain their initial body mass. This may be due to a general cyclic variation in body weight found in mammals that are adapted to seasonal variation in food supply (e.g. seasonal changes in body weight of farmed mink, Korhonen and Niemelä, 1998), a phenomenon also found in captive animals when fed ad libitum (e.g. Korhonen and Harri, 1986). Also, heavier foxes lost more weight than lighter ones, a finding that was most pronounced in the excessive fed foxes. Alternatively, if the foxes perceived the experimental procedure as stressful (to little or too much food and close human presence) this could, in principle, negatively affect feed utilisation and lead to a general weight loss seen in both groups (cf. negative effects of stress on gut absorption and nutrient intake, Elsasser et al., 2000). We judge this possibility to be rather unlikely because the experimental subjects did not show any obvious signs of stress during the experimental period. They were adult vixens that were previously habituated to the presence of people by repeatedly hand feeding of titbits. In addition, only familiar persons fed the foxes during the study and they were habituated to the feeding procedure for 8 days prior to the start of the experiment. Thus, the feeding procedure was highly predictable to the foxes and should therefore minimize the possibility for inducing fear and stress in the subjects.

\section{Experiment 2: does the presence of food affect the foxes' use of a cage?}

\subsection{Materials and methods}

\subsubsection{Animals and housing}

Five 2-year-old silver fox males of a domesticated line (Trut, 1999) were chosen as experimental subjects. During the study the subjects were housed continuously inside an operant apparatus for foxes (Fig. 2) (for a thorough description of the operant apparatus see Hovland, 2005; Hovland et al., 2006). These males were previously used in several operant tests and were familiar with the test cages and the operant response. Inside the operant cage two operant pulling devices, a rubber coated metal chain shaped as a loop, were mounted on the opposite sides, each one governing the opening of a door leading to one of

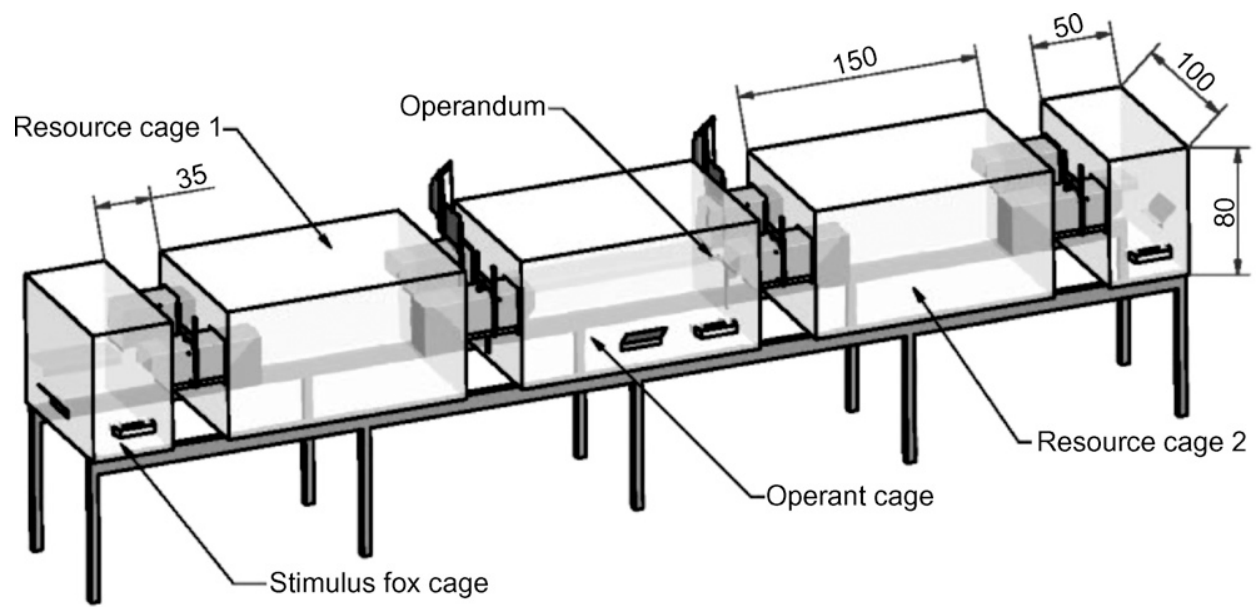

Fig. 2. The operant apparatus. During Experiment 2 the fox could access resource cages 1 and 2, whereas access to additional cages (labelled the stimulus fox cages) was denied. Operandum = pulling device. 
two adjacent cages. Each time the subject pulled the loop once (FR1) the door opened and stayed open for $10 \mathrm{~s}$ for the fox to enter one of two identical resource cages. During the test the subjects had access to the operant cage and two adjoining resource cages (labelled resource cages 1 and 2, Fig. 2). The stimulus fox cages were not used during this study. The gates leading back to the operant cage were locked with an electrical lock, and to open the door the subjects were equipped with a collar $(120 \mathrm{~g})$ transmitting Infraredbeam codes. The subjects had access to a mesh resting shelf inside the operant cage. Water was available in drinking cups mounted inside the operant cage and was replenished three times a day. Five parallel apparatuses were used during the study and they were placed in parallel rows $2 \mathrm{~m}$ apart inside the same barn, such that the subjects could see and hear each other during the experiment.

\subsubsection{Experimental procedure}

To test whether the presence of excess food affected the subjects' use of the resource cage the following procedure was chosen. Each day at approximately 10:00 a.m. the subjects were fed a ration of $800 \mathrm{~g}$ standard feed paste for fur animals (Pelsdyrfor Hamar AB). The food was offered in a metal bowl (diameter $24 \mathrm{~cm}$ ) tethered with wire to the cage floor inside one of the resource cages. The subjects had to pull the operant device once to access the food. The quantity of food given was approximately $60 \%$ above maintenance and this amount was given to assure that food was constantly available. Because the foxes could see and hear each other during testing we controlled for the effect of social facilitation (i.e. a tendency to copy the behaviour of others) by balancing the position of the food tray. In apparatus no. 1 the start position of the food bowl was in the left resource cage, in apparatus no. 2 the start position was to the right, in apparatus no. 3 the start position was in the left, etc. During the experiment the position of the food tray was switched five times from resource cage 1 to resource cage 2 (or vice versa) within each apparatus in a random order to avoid a possible effect of habituation as according to Table 1. The switching of the food bowls was completed between 09:00 and 10:00 a.m. The bowls were loosened from the cage floor, taken out and positioned in the opposite resource cage by wiring it to the cage floor. Four of the foxes were tested for 18 days whereas one fox were taken out the 17th test day because of an empty collar battery. Prior to the start of the experiment the subjects were housed inside the apparatus for 4 days to habituate. The experiment was completed from 02 to 24 July 2004 at the University Fur Animal Research Farm (Centre for Farm Animal Research, SHF).

\subsubsection{Data collected}

The gates leading to the resource cage and back to the operant cage were mounted with micro switches for recording of time for entries and exits. When the subjects entered the gate the micro switches were activated and the exact time (hh-mm-ss) was logged to a computer file. Subsequently, the total time spent per day inside the resource cages was calculated for each subject and treatment (food present/food not present). Also, number of visits to the resource cages and the mean duration per visit were calculated for each subject and treatment.

\subsubsection{Statistical analysis}

For the statistical analysis the total time inside the cage and visit number per day and treatment was averaged for each animal. For each fox total time spent in each cage was assessed and 'food' and 'empty'

Table 1

The switching (S) of the food bowl position between resource cages 1 and 2 during the experimental period

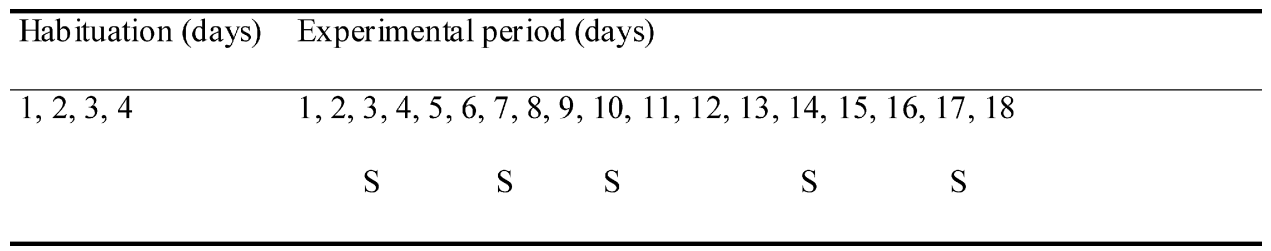



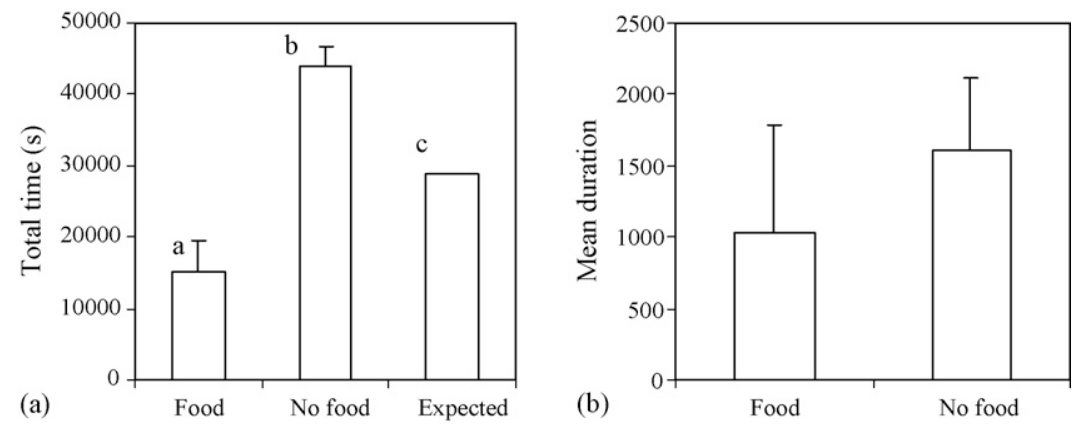

Fig. 3. (a) Experiment 2: total time spent inside the resource cage when food was present and absent, including the expected amount of time to be spent inside the cage on random $(8 \mathrm{~h})$. Different letters signify significant differences between the treatments $(P<0.05)$. (b) The mean visit duration to the resource cages when food was present and absent.

cages were compared with paired $t$-tests. For a stricter test we tested whether time spent inside the cage with food were lower compared to the expected value $(24 \mathrm{~h} / 3$ available cages $=8 \mathrm{~h})$ using paired $t$-tests. The effect of treatment on number of visits and visit duration to the cages was also tested with a paired $t$-test. Mean values are given with standard errors (SE). SAS ${ }^{\mathbb{R}}$ Enterprise Guide V2 was used for the statistical analyses.

\subsection{Results}

Total time spent with food was significantly different from the amount of time spent inside the cage when empty $\left(t_{4}=4.43, n=5, P=0.012\right.$, Fig. 3a). Also, the total time spent inside the food cage was significantly different from the expected time $(8 \mathrm{~h})\left(t_{4}=3.19, n=5, P=0.033\right.$, Fig. 3a). The mean duration of visits to the food was lower, although not significantly $\left(t_{4}=2.29, n=5\right.$, $P=0.084$, Fig. $3 b$ ). There was, however, no difference in visit frequency to the cages dependent on whether the food was present or not $\left(t_{4}=0.59, P=0.587\right)$, and the mean visit number was $40.1 \pm 6.1$ per $24 \mathrm{~h}$.

\subsection{Discussion, Experiment 2}

The results confirmed (cf. Hovland et al., 2006) that domesticated silver fox males avoided staying for longer periods with food, and stayed nearly three times as long in the cage when it was empty than when it contained food. However, the visit frequency to the cage was not affected by the presence or absence of food. Since the food bowl only took up approximately $3 \%$ of the floor area it is not likely that it precluded preferred activities like e.g., lying down. Instead, the result seems to confirm that the presence of food makes that part of the apparatus aversive at times when food is not eaten. As mentioned in the introduction, in their natural habitat, foxes are known to dig holes to hide food (caches) when abundance is high (Macdonald, 1976; Sklepkovych and Montevecchi, 1996). Cache behaviour is also recorded in captive-reared red foxes housed in earthen enclosures (Jeselnik and Brisbin, 1980). The importance of this behaviour to captive animals is unknown, although in Fennec foxes (Fennecus zerda), some forms of post-feeding stereotypic pacing have been suggested to arise from thwarted caching motivations (Carlstead, 1991). However, digging is frequently observed in farmed foxes (e.g. Korhonen et al., 2001), both on the wire mesh floor and on ground substrates, although its motivational basis (e.g. exploration, food hiding, digging dens, escape) is as yet unknown. One possibility is therefore that uncached food is avoided except during eating, either because it elicits frustration (due to the impossibility 
of true caching) or because naturally, it would not be adaptive to stay near to exposed food due to the risk of intra- and inter-specific competition and aggression. Alternatively, it is not the food's uncached nature that is inherently important, but how its properties change when exposed all day. 'Leftovers' may thus have a poorer nutritional value, and therefore not highly valued or even become aversive.

\section{General discussion and conclusions}

Overall, these two experiments show that the presentation of ad libitum food to silver foxes can have some unexpected effects, increasing day-to-day variability in food consumption, and potentially even being aversive at times when the animal is not hungry. This could help explain why we obtained more consistent and explicable measured values of food preference when the food was offered in relatively small portions each day (Hovland et al., 2006) then when food was offered ad libitum (Hovland, 2005). The implications for using food paste as a yardstick resource for silver foxes is that the ration should be held at maintenance, or just above, to compensate for the energy being used for operant work without risking that the subjects become satiated for very long periods, or that excess food even becomes aversive. Preferably, the appetite of the subjects should be monitored on an individual level to standardise the feeding motivation, i.e. in case of food leftovers the ration could be slightly reduced the following day. Another implication for the design of future motivation test is that aversion to stay with food in the operant chamber might trigger operant responding to get out of the cage, confounding this motivation with the motivation to get in to the test resource. An empty resource cage made concurrently available distant from food would control for this.

The findings from Experiment 2 are intriguing in terms of what they reveal about foxes, and need further investigation. Since our subjects originated from a domesticated line (Trut, 1999) and are not selected for food utilisation and growth to the same extent as the Norwegian commercial line it is interesting to investigate whether this apply to farmed silver foxes in general. If they do, it would also be interesting to examine some possible motivational bases for avoiding excess food, e.g. whether excess food affects digging frequency (cache motivation) or if properties of the food it self (fresh versus leftovers) affect avoidance.

\section{Acknowledgements}

The studies were supported by the Norwegian Research Council and the Norwegian Fur Breeders' Association. Thanks to research assistants Arve Halstvedt and Margrethe Brynem for monitoring the experiments and for taking good care of the animals during the study periods.

\section{References}

Burger, I.H., 1993. A basic guide to nutrient requirements. In: Burger, I.H. (Ed.), The Waltham Book of Companion Animal Nutrition. Pergamon Press Ltd., Oxford, UK.

Carlstead, K., 1991. Husbandry of the Fennec fox Fennecus zerda: environmental conditions influencing stereotypic behaviour. Int. Zoo Yearbook 30, 202-207.

Dawkins, M.S., 1983. Battery hens name their price: consumer demand theory and the measurement of ethological 'needs'. Anim. Behav. 31, 1195-1205.

Elsasser, T.H., Klasing, K.C., Filipov, N., Thompson, F., 2000. The metabolic consequences of stress: targets for stress and priorities of nutrient use. In: Moberg, G.P., Mench, J.A. (Eds.), The Biology of Animal Stress: Basic Principles and Implications for Animal Welfare. CABI Publishing, Oxon, UK. 
Hovland, A.L., 2005. Development and evaluation of an operant method to measure social motivation in farmed silver foxes (Vulpes vulpes). Dr. Scientiarum Theses 2005, p. 14, Norwegian University of Life Sciences, ISBN: 82-5750656-7.

Hovland, A.L., Mason, G., Bøe, K.E., Steinheim, G., Bakken, M., 2006. Evaluation of the maximum price paid as an index of motivational strength for farmed silver foxes (Vulpes vulpes). Appl. Anim. Behav. Sci. 100, $258-279$.

Jeselnik, D.L., Brisbin Jr., I.L., 1980. Food-caching behaviour of captive reared red foxes. Appl. Anim. Ethol. 6, 363-367.

Kauhala, K., Laukkanen, P., von Rege, I., 1998. Summer food composition and food niche overlap of the raccoon dog, red fox and badger in Finland. Ecography 21, 457-463.

Korhonen, H.T., Harri, M., 1986. Seasonal changes in energy economy of farmed polecat as evaluated by body weight, food intake and behavioural strategy. Physiol. Behav. 37, 777-783.

Korhonen, H.T., Niemelä, P., 1998. Effect of ad libitum and restrictive feeding on seasonal weight changes in captive minks (Mustela vison). J. Anim. Physiol. A: Anim. Nutr. 79, 269-280.

Korhonen, H.T., Niemelä, P., Jauhiainen, L., 2001. Effect of space and floor material on the behaviour of farmed blue foxes. Can. J. Anim. Sci. 81, 189-197.

Littell, R.C., Milliken, G.A., Stroup, W.W., Russel, D., Wolfinger, R.D., 1996. SAS System for Mixed Models. SAS Institute Inc., Cary, NC.

Macdonald, D.W., 1976. Food caching by red foxes and some other carnivores. Z. Tierpsychol. 42, 170-185.

Mason, G.J., Cooper, J., Clarebrough, C., 2001. Frustrations of fur-farmed mink. Nature 410, 35-36.

Matthews, L.R., Ladewig, J., 1994. Environmental requirements of pigs measured by behavioural demand functions. Anim. Behav. 47, 713-719.

Nieminen, P., Asikainen, J., Hyvarinen, H., 2001. Effects of seasonality and fasting on the plasma leptin and thyroxin levels of the raccoon dog (Nyctereutes procyonoides) and the blue fox (Alopex lagopus). J. Exp. Zool. 289, $109-118$.

Pedersen, L.J., Jensen, M.B., Hansen, S.W., Munksgaard, L., Ladewig, J., Matthews, L., 2002. Social isolation affects the motivation to work for food and straw in pigs as measured by operant conditioning techniques. Appl. Anim. Behav. Sci. 77, 295-309.

Sklepkovych, B.O., Montevecchi, W.A., 1996. Food availability and food hoarding behaviour by red and arctic foxes. Arctic 49, 228-234.

Trut, L.N., 1999. Early canid domestication: the farm-fox experiment. Am. Sci. 87, 160-169.

Warburton, H.J., Mason, G., 2003. Is out of sight out of mind? The effects of resource cues on motivation in mink, Mustela vison. Anim. Behav. 65, 755-762. 